\title{
ACNE ROSACEA KERATITIS AND RIBOFLAVINE. (VITAMIN B2)
}

\author{
BY \\ WINIFREDE M. FISH \\ OXFORD
}

IN a paper on " Rosacea Keratitis and Conditions with Vascularisation of the Cornea" 1 it is stated by Johnson and Eckardt that "thirty-six patients with rosacea keratitis were treated by the addition of riboflavine to the diet. Of these, nine also showed some cutaneous type of rosacea. Thirty-two of these patients had prompt healing of the corneal lesions "-usually within four days. "Of the thirty-six patients studied, only two gave a history of having eaten adequate amounts of egg white, liver and milk." It is inferred by the authors that " rosacea keratitis (so called) may be the direct result of deficiency of riboflavine."

In a subsequent communication ${ }^{2}$ Johnson, referring to a paper by Sydenstricker and others on "The Ocular Manifestations of Ariboflavinosis,"3 says that " changes in the cornea are described which appear to be identical with rosacea keratitis," and that " the term ' dietary keratitis' (used by Sydenstricker) appears to initiate a new designation of the condition familiar to ophthalmologists as rosacea keratitis, so called."

This seemed rather surprising, in. view of the fact that in the Southern States of America, where riboflavine deficiency is common, acne rosacea is a rare disease and is not even mentioned in Sydenstricker's paper.

A series of forty-five cases of acne rosacea were therefore examined with the slit-lamp in order to find out whether they showed the type of corneal vascularisation demonstrated to the present writer by Sydenstricker as diagnostic of ariboflavinosis, i.e., a bilateral, symmetrical, superficial-proliferation of new streamer-liké fine vessels from the limbal loops, forming a more or less regular pattern all round the cornea and extending towards its centre.

Of these forty-five cases all had the cutaneous lesions, and all but two had the corneal lesions typical of rosacea, but only three had bilateral corneal involvement, so that in forty cases there was a control eye uncomplicated by ulceration in which to look for the corneal vascularisation typical of ariboflavinosis, which, though not always equal, is always bilateral.

This type of vascularisation was absent in all forty cases.

Ten of these patients were treated with riboflavine alone in the dosage prescribed by Johnson and Eckardt, no local treatment being given, and-probably owing to the deprivation of atropine 
under test conditions - these patients became so much worse within a week that routine treatment consisting of atropine, dark glasses, sulpho-calamine lotion (for the skin) and dilute hydrochloric acid (to be sipped with meals) had to be added to the vitamin B2 therapy, after which they, and twenty-three other cases similarly treated, healed within varying periods.

Ten other cases healed on routine treatment without riboflavine in about the same time.

One case (No. $1(b)$ ), with cutaneous rosacea but without corneal involvement of any kind, was untreated.

Analysis of 45 Cases of Rosacea

\begin{tabular}{c|c|c|c}
\hline & $\begin{array}{c}\text { Bilateral } \\
\text { Keratitis }\end{array}$ & $\begin{array}{c}\text { Unilateral } \\
\text { Keratitis }\end{array}$ & No Keratitis \\
\hline $\begin{array}{c}\text { With Corneal } \\
\text { Vascularisation }\end{array}$ & 0 & 0 & $1(a)$ \\
$\begin{array}{c}\text { Without Corneal } \\
\text { Vascularisation }\end{array}$ & 3 & 40 & $1(b)$ \\
\hline
\end{tabular}

"Corneal vascularisation" here means the bilateral type found in ariboflavinosis (with or without the localised type found in rosacea).

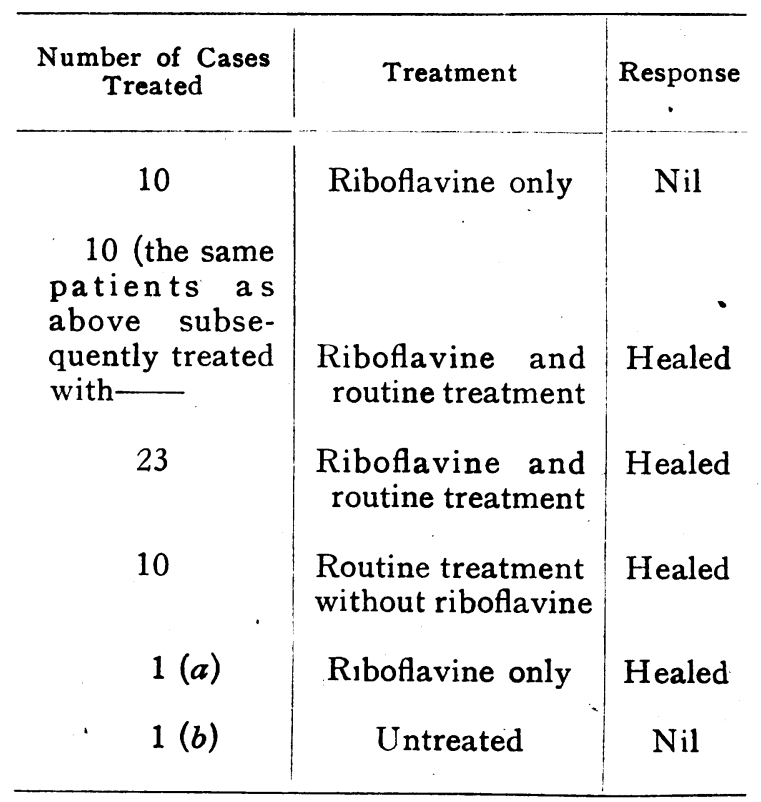




\section{Acne Rosacea Keratitis and Riboflavine}

One case (No. $1(a)$ ), with slight cutaneous rosacea and with the corneal vascularisation typical of ariboflavinosis but without keratitis, was treated with riboflavine alone and within a month the corneal vessels were visible only as "ghosts" ; the cutaneous condition remained unchanged. This was the only case in which gastric hypochlorhydria was improbable but riboflavine deficiency likely to occur, as the patient had slight symptoms of duodenal ulcer. It was the only case of the series which responded to treatment with riboflavine alone.

In the group of twenty-three cases, two required peritomy and one failed to heal until tonsillectomy was performed.

Seven of the series were examined by Sydenstricker, who confirmed ariboflavinosis only in case $1(a)$, which was not a case of rosacea keratitis, and was the only one to respond to riboflavine therapy.

\section{Conclusion .}

It is to be noted that, in the present series of forty-five cases of rosacea, there was only one which had the clinical signs and a history suggestive of riboflavine deficiency, whilst all had cutaneous rosacea; whereas in the series of thirty-six cases published by Johnson and Eckardt, thirty-four gave histories suggestive of a deficiency of this vitamin in their diet, and only nine " showed some cutaneous type of rosacea."

In the more recent contribution by Johnson ${ }^{4}$ the deseription of the corneal lesions is typical of rosacea keratitis even in the absence of confirmatory cutaneous lesions, but the type of corneal vascularisation diagnostic of ariboflavinosis is nowhere mentioned by Johnson, nor does he state the condition of the unaffected eye in unilateral cases of " so called" rosacea keratitis.

It has recently been established ${ }^{5}$ that the concentration of vitamin $\mathrm{B} 2$ in the corneal epithelium of the ox is very high as compared with other parts of the eye, and it may be that in patients with corneal lesions who are already generally deficient in this vitamin owing to faulty diet, or who may be locally deficient in it owing to injury to the corneal epithelium; riboflavine therapy promotes healing of the cornea; but in this present series of forty-five cases, rosacea keratitis does not appear to be the direct result of ariboflavinosis.

\section{REFERENCES}

1. Johnson and ECKardT.-Arch. of Ophthal., May, 1940, Vol. XXIII.

2. Arch. of Ophthal., November, 1940, Vol. XXIV.

3. Sydenstricker, Sebreld, Cleckley and Kruse. Jl. Amer. Med. Assoc., June, 1940, Vol. CXIV.

4. Johnson.-Amer. Jl. of Ophthal., November, 1941, Vol. XXIV.

5. Pirrie (pending publication). - The figure obtained for corneal epithelium is $2 \gamma$ per gramme wet weight; this is much higher than in the surrounding ocular tissue including the aqueous. 